\title{
Health-related quality of life and physical functioning in people living with HIV/AIDS: a case-control design
}

\author{
Chidozie Emmanuel Mbada ${ }^{*}$, Olaniyi Onayemi ${ }^{2}$, Yewande Ogunmoyole $^{3}$, Olubusola Esther Johnson ${ }^{1}$ \\ and Christopher O Akosile ${ }^{4}$
}

\begin{abstract}
Background: Health-Related Quality of Life (HRQoL) and functional exercise capacity are important area of therapeutic interventions needed to improve the general health of People Living with HIV/AIDS (PLWH). However, the relationship between self-report and Performance-based Measure of Functional Capacity (PMFC) of PLWH is still obscure. This study compared the HRQoL and PMFC between a homogenous sample of clinical stage I PLWH and apparently healthy controls.

Methods: This case-control study involved 74 consenting participants (37 PLWH and 37 controls) who completed the self-report SF-12 questionnaire and PMFC assessment using Six Minute Walk Test (6MWT). PMFC was expressed in terms of Six-Minute Walk Distance (6MWD), Six-Minute Walk Work (6MWW) and Maximum oxygen uptake $\left(\mathrm{VO}_{2} \mathrm{max}\right)$. Data were analyzed using descriptive statistics of mean and inferential statistics of independent $t$-test, ANOVA and Pearson's product moment correlation. Alpha level was set at 0.05 .

Results: There was no significant difference in the SF-12 Physical-health Component Score (PCS) of PLWH and the controls $(p=0.782)$. However, the SF-12 Mental-health Component Score (MCS) of PLWH was higher than that of controls $(p=0.040)$. 6MWD, 6MWW and $\mathrm{VO}_{2}$ max were significantly lower for PLWH $(p<0.05)$. Among PLWH, there was no significant gender differences in the PMFC ( $p>0.05)$ while PCS was higher among females. There was no significant correlation between PMFC variables and each of PCS and MCS for PLWH and controls ( $p>0.05)$ respectively.

Conclusion: Self-report physical health of clinical stage 1 PLWH and controls was comparable, while self-report mental health capacity was higher in PLWH than the controls. PMFC of PLWH was significantly lower compared to healthy controls without gender bias. Overall, self-report and performance-based measure of physical functional capacity of PLWH was not inter-related. Therefore understanding the factors that may influence exercise capacity of PLWH may help to develop effective exercise programmes for PLWH.
\end{abstract}

Keywords: Functional exercise capacity, HIV/AIDS, 6MWD, SF-12

\section{Background}

The Human Immune-deficiency Virus/Acquired Immunodeficiency Syndrome (HIV/AIDS) epidemic is on the increase around the world with about 33.2 million people living with the disease worldwide [1,2]. Africa is the most affected region with 1.8 - 1.9 million people living with HIV [3]. As at 2003, Nigeria was estimated to

\footnotetext{
* Correspondence: doziembada@yahoo.com

${ }^{1}$ Department of Medical Rehabilitation, College of Health Sciences, Obafemi Awolowo University, lle - Ife, Nigeria

Full list of author information is available at the end of the article
}

have the third highest number of people living with HIV/ AIDS in the world, after South Africa and India [4]. There are varying reports on the prevalence rate of HIV/AIDS in Nigeria in the recent years; however, all the reports suggest an upward trend in the prevalence $[3,5,6]$. The WHO estimates that $3.1 \%$ of adults aged $15-49$ years are HIV positive in Nigeria [3].

HIV/AIDS is a life-long disease that poses severe threats to the health of millions ensuing in morbidity and mortality around the world [7] and it maintains an insolent stance against interventions as no cure or vaccine has

\section{() Biomed Central}


been found for it [7-9]. However, there are praiseworthy advances in medical and pharmacological management of patients with HIV/AIDS with reported successes but not without attendant costs and adverse side effects [10,11]. Complementarily, therapeutic exercise is one of the approaches being explored to help deal with the complications and symptoms of HIV/AIDS [12]. The HIV infects cells of the immune system, destroying or impairing their function leading to progressive deterioration of the immune system called "immune deficiency" [3]. Presentations associated with chronic HIV infection that eventually lead to disability and mortality includes muscle wasting, muscle weakness, fatigue, impaired functional work capacity, depression and decreased quality of life [7].

Various reports have shown that the presence of HIV/ AIDS as well as the symptoms and complications associated with HIV/AIDS have a negative effect on the quality of life of People Living with HIV/AIDS (PLWH) [6-9]. Health-Related Quality of Life (HRQoL) refers to quality of life in a clinical setting that includes those dimensions such as global health perceptions, symptom status, functional status, biologic and physiologic variables, individual and environmental characteristics directly affected by the overall state of health $[13,14]$. Research on health-related outcomes such as HRQoL and functional exercise capacity of PLWH are acclaimed to be significant areas for therapeutic intervention needed to improve the general health of PLWH $[15,16]$.

Functional exercise capacity is believed to be depressed in PLWH [17-19]. The mechanism explaining the relationship between HIV/AIDS and functional exercise capacity is somewhat intricate and complex. Meanwhile, the pathophysiology of the decreased functional exercise capacity has been associated with the effects of HIV/AIDS on anaerobic metabolism, muscle fatigue, and eventual muscle wasting in PLWH [20-23]. Similarly, the immune system of the PLWH and several immunological variables including HIV-1 ribonucleic acid viral load and CD4 cell count has been implicated for decreased functional exercise capacity in PLWH [24,25]. Furthermore, there are available reports suggesting that psychological health such as quality of life decreases as HIV/AIDS progresses, and this may affect the exercise capacity of PLWH [16,20-22,26].

An assessment of functional exercise capacity and the factors that may influence the outcome of exercise in PLWH are required in designing an exercise program. The Six Minute Walk Test (6MWT) has been accepted as one of the important performance-based tool in the assessment of functional exercise capacity and it has been used extensively in various populations including $\mathrm{HIV} /$ AIDS [27,28]. In the same vein, patient's self-reported functional capacity assessed using questionnaires based on indicators of functioning on different activities of daily living have been reported in some studies as valid [29-32]. However, comparison of performance-based and self-rated functional capacity has been reported in literature but with variable results [32-34]. In addition, discrepancies exist in literature as to what extent self-reporting can replace performance based testing [35]. However, there is an apparent dearth of studies comparing self-report and Performance-based Measure of Functional Capacity (PMFC) of PLWH. This study compared the HRQoL and PMFC between a homogenous sample of clinical stage I PLWH and apparently healthy controls.

\section{Methods}

A total of 74 participants (37 PLWH (15 (40.5\%) males and 22 (59.5\%) females) and 37 age and sex matched apparently healthy controls) volunteered for the study. Consenting PLWH in this study were recruited from the Virology Research Clinic (VRC) of Obafemi Awolowo University Teaching Hospitals Complex (OAUTHC) IleIfe, Nigeria. In order to ensure homogeneity of sample, PLWH in clinical stage I of the disease who were 18 years and older and were recruited. Clinical stage I of HIV/AIDS refers to asymptomatic/acute HIV infection, with persistent generalized lymphadenopathy [36,37]. All the PLWH volunteers were on anti-retroviral therapy (HAART). Consenting participants that had a history of unstable angina and myocardial infarction during the previous month and those that were already involved in an exercise program were also excluded. The apparently controls in this study included patients' relatives and health workers at the VRC. The ethical approval for this study was obtained from the ethical committee of the OAUTHC. The VRC gave permission for the study to be carried out at the centre. Each participant gave informed consent to participate in the study. The participants' ages were recorded while weight and height were also measured and recorded.

Health-Related Quality of Life (HRQoL) was assessed using the Medical Outcomes Study Short-Form 12 questionnaire (SF-12). As a generic instrument, the SF-12 has been shown to be valid in both apparently healthy individuals and PLWH [38-40]. The SF-12 is a 12-item version of the Medical outcomes study Short Form-36 (SF-36) addressing physical functioning, role limitations due to physical health, role limitations due to emotional health, social functioning, bodily pain, general health perceptions, vitality, and mental health [40-42]. The SF-12 reduces item redundancy and the burden of data requirements for both investigators and patients [41]. The SF-12 yields two summary scores; the Physicalhealth Component Score (PCS) and the Mental-health Component Score (MCS). The participants filled the questionnaire between 2-3 minutes while sitting comfortably on a chair. The PCS of the SF-12 was used 
in this study as a measure of self-report functional capacity.

Performance-based Measure of Functional Capacity (PMFC) was assessed using the 6-minute walk test (6MWT) in accordance with the American Thoracic Society [43]. This test measures the distance that a participant can quickly walk on a flat, hard surface in a period of 6 minutes referred to as the 6-minute walk distance (6MWD). A distance of $30 \mathrm{~m}$ was marked on the hallway with white chalk. The participants were then asked to walk back and forth in the hallway for six minute from one end of the $30 \mathrm{~m}$ distance mark to another, pivoting briskly at each end and continue walking without hesitation. Participants that became exhausted were permitted to slow down, to stop, and to rest as necessary. They were allowed to lean against the wall while resting, but resume walking as soon as they were able to. If the participant stopped before the 6 minutes were up and refused to continue, a chair was taken to the participant to sit on, and the walk discontinued. When the test was completed, the spot where the participant stopped was marked and the total distance walked (i.e. 6MWD) in meters was recorded. No encouragement was given during the performance of the test. Data from participants that fail to complete the test were excluded from analysis. PMFC was expressed in terms of Six-Minute Walk Distance (6MWD), Six-Minute Walk Work $(6 \mathrm{MWW})$ and Maximum oxygen uptake $\left(\mathrm{VO}_{2} \mathrm{max}\right)$.

\section{Computations}

I.

$$
\begin{aligned}
& \text { Six Minute Walk Work }(6 \mathrm{MWW})(\mathrm{kg} / \mathrm{m}) \\
& =6 \mathrm{MWD} \times \text { body weight }
\end{aligned}
$$

[44].

II.

Maximum oxygen uptake $\left(\mathrm{VO}_{2} \mathrm{max}\right)(\mathrm{mL} / \mathrm{kg} /$ minute $)$ $=(\operatorname{speed}(\operatorname{mmin}-1) \mathrm{X} 0.1)+3.5$

[45].

\section{Statistical analysis}

Statistical Package for Social Sciences (SPSS) software (version 16) was used for the data analysis. Data were analyzed using descriptive statistics of mean and standard deviation. Inferential statistics of independent $t$-test was used to compare variables between the PLWH and their healthy controls. One-Way ANOVA and LSD post-hoc comparison was used to compare variables between groups and by gender. Pearson's product moment correlation analysis was used to test the relationships between variables. Alpha level was set at $\mathrm{p}<0.05$.

\section{Results and discussion \\ Result}

The participants' ages ranged between 20 and 54 years. The physical characteristics of the participants are presented in Table 1 . The PLWH and their healthy controls were comparable in age, weight, height and body mass index ( $\mathrm{p}>0.05)$.

The independent $t$-test comparison of the PCS and MCS between the PLWH and control group are shown in Table 2. The control group had a higher PCS than the PLWH $(51.92 \pm 7.35$ vs. $52.40 \pm 7.61)$ but was not statistically significant $(\mathrm{p}>0.05)$. The MCS of the PLWH was found to be significantly higher than the MCS of the control group ( $\mathrm{p}=0.04)$. Table 3 shows the independent $t$-test comparison of performance-based measures of functional capacity between the PLWH and control group. From the result, the control group had significantly higher 6MWD, $6 \mathrm{MWW}$ and $\mathrm{VO}_{2}$ max respectively $(\mathrm{p}=0.001)$.

One-Way ANOVA and LSD post-hoc comparison of the performance-based functional exercise capacity measures, PCS and MCS by gender is presented in Table 4 . LSD post-hoc test was used to elucidate where the differences observed in the F-ratio lies. From the result, there were no significant gender differences in 6MWD, 6MWW and $\mathrm{VO}_{2}$ max among PLWH ( $\mathrm{p}>0.05$ ). However, female participants with HIV/AIDS had significantly higher PCS (48.97 \pm 8.33 vs. $53.92 \pm 5.99$; $\mathrm{p}<0.05$ ) while MCS was comparable ( $\mathrm{p}>0.05$ ). On the other hand, the male controls had significantly higher values for 6MWD, 6MWW and $\mathrm{VO}_{2} \max (\mathrm{p}<0.05)$ respectively, while PCS and MCS were comparable between both gender $(\mathrm{p}>0.05)$. Pearson product moment correlation between functional exercise capacity variables (6MWD, 6MWW and $\mathrm{VO}_{2} \max$ ) and each of PCS and MCS is shown in Table 5. From the result, there was no significant correlation between PCS and the performance-based functional capacity measures for the PLWH and control groups respectively $(p>0.05)$. Also, there was no significant correlation between MCS and

Table 1 Independent $t$-test comparison of the general characteristics of PLWH and control group

\begin{tabular}{lllll}
\hline & PLWH & Control group & & \\
Variable & $\mathbf{X} \pm$ SD & $\mathbf{X} \pm$ SD & $\mathbf{t}$ - cal & p-value \\
\hline Age & $35.68 \pm 7.71$ & $35.73 \pm 7.88$ & -0.30 & 0.976 \\
HT & $1.67 \pm 0.79$ & $1.66 \pm 0.08$ & 0.344 & 0.739 \\
WT & $63.49 \pm 12.25$ & $67.12 \pm 11.35$ & -1.324 & 0.190 \\
BMI & $22.77 \pm 4.17$ & $24.31 \pm 4.24$ & -1.583 & 0.118 \\
\hline
\end{tabular}

Abbreviations: HT Height, WT Weight, BMI Body mass index. 
Table 2 The independent $t$ test comparison of the PCS and MCS of PLWH and control group

\begin{tabular}{lllll}
\hline & PLWH & Control group & & \\
Variable & $\mathbf{X} \pm$ SD & X \pm SD & t-cal & p-value \\
\hline PCS & $51.92 \pm 7.35$ & $52.40 \pm 7.61$ & -0.277 & 0.782 \\
MCS & $73.00 \pm 13.00$ & $65.26 \pm 9.27$ & 2.952 & $0.040^{*}$ \\
\hline
\end{tabular}

* Indicates significant difference between groups.

Abbreviations: PCS Physical-health Component Score, MCS Mental-health Component Score.

the performance-based functional capacity for the PLWH and control groups respectively ( $p>0.05)$.

\section{Discussion}

This study assessed the HRQoL and PMFC of a homogenous sample of clinical stage I PLWH and their age-and-sex matched healthy controls. The PCS of the SF-12 was employed in this study as a self-report measure of physical functional capacity. From the result, there was no significant difference in the PCS between PLWH and the controls. The finding on comparable PCS between the PLWH and the controls may be a reflection of the clinical stage of the PLWH. Several studies using the SF-12 have shown that physical and mental capacity decreases as the severity of HIV/AIDS increases [46-49]. This present study recruited a homogenous sample of PLWH in clinical stage 1 [asymptomatic stage] who were currently on anti-retroviral therapy [HAART]. The symptoms and complications of HIV/AIDS including muscle wasting, fatigue and disability as well as prevalence of opportunistic infections have been shown to be significantly reduced with the introduction of highly active HAART [46,50]. It is adduced that the asymptomatic stage and the effect of the HAART in retarding the progression of HIV/AIDS disease may have led to the comparable self-reported physical capacity between PLWH and the controls. Furthermore, the comparable PCS among the groups may be due to the young age of the participants. In a cross sectional study, Nojomi et al. [48] found PLWH below age 35 years to have significantly better PCS than other age groups. The mean age (35.68 \pm 7.71 years) of PLWH that participated

Table 3 Independent $\boldsymbol{t}$-test comparison of the measures of functional exercise capacity between PLWH and control group

\begin{tabular}{|c|c|c|c|c|}
\hline & PLWH & Control group & & \\
\hline Variable & $\mathrm{X} \pm \mathrm{SD}$ & $\mathrm{X} \pm \mathrm{SD}$ & t - cal & $p$-value \\
\hline 6MWD & $442.95 \pm 93.32$ & $556.07 \pm 93.41$ & -5.211 & $0.001^{*}$ \\
\hline 6MWW & $27853 \pm 7501.63$ & $37056 \pm 7433.32$ & -5.301 & $0.001^{*}$ \\
\hline $\mathrm{VO}_{2} \max$ & $30.07 \pm 5.60$ & $36.86 \pm 5.60$ & -5.211 & $0.001^{*}$ \\
\hline
\end{tabular}

* Indicates significant difference between groups.

Abbreviations: $6 M W D 6$ minute walk distance, $6 M W W 6$ minute walk work, $\mathrm{VO}_{2}$ max Peak oxygen uptake. in this study is similar to that reported by Nojomi et al. [48] as having better physical capacity than older PLWH.

The result of this study showed that the self-reported MCS of PLWH was significantly higher than the healthy controls. This finding contradicts the results of previous studies that have found low mental health in PLWH [51-54]. However, similar to the finding of this study, Ostrow et al. [55] found that HIV/AIDS had a negative effect on the physical health of PLWH, but not on their mental health and attributed finding to the positive effect of HAART on the mental functioning of PLWH. HAART has been reported to have a positive effect on the life expectancy of PLWH, changing the view of HIV/ AIDS from a deadly disease to a potentially manageable disease and consequently lead to improved survival and reduction in opportunistic infections [47]. Apart from the stage of no/minimal presence of symptoms of HIV/ AIDS, accessibility to HAART by PLWH at the clinic where this study was conducted may have led to improvement in the PLWH perspective of the disease resulting in a reported better mental health capacity. In addition, the trend of people with terminal illnesses such as HIV/AIDS towards a more spiritual disposition may also explain the significantly higher mental health capacity of PLWH found in this study. Nigeria is a religious country where nearly everyone belongs to one religion or the other. Anecdotal and empirical reports indicated that Nigerian patients with chronic illnesses have high level of religious inclinations [56,57]. High levels of religious inclinations have been reported among patients with HIV/AIDS [58-62]. The possible religious disposition portends that PLWH may translate into being positive-minded and over-psyched. PLWH often adopt spirituality as a coping strategy to help reframe their lives and also to bring a sense of meaning and purpose to their lives in the face of an often devastating situation [63-65]. Some other studies have found spirituality to be positively associated with improvements in life satisfaction, functional health status, health-related quality of life, and overall well-being in PLWH $[57,60,66,67]$. Anecdotally, most of the patients seen in the course of this study often speak in terms of their anticipation for better health rather than accepting the present realities of the HIV/AIDS infection. This form of communication may account for the higher mental health component in PLWH compared with the controls.

From this study, performance-based functional capacity [6MWD, 6MWW and $\mathrm{VO}_{2} \max$ ] of PLWH was found to be significantly lower than that of the controls. The result on lower functional capacity among PLWH is consistent with previous reports [68-70]. Specifically, from the result of this study, 6MWD by the PLWH was significantly shorter than that of the controls. This may be attributed to muscle wasting and weakness, increased muscular 
Table 4 One-Way ANOVA and LSD post-hoc comparison of performance-based functional exercise capacity measures, PCS and MCS by gender

\begin{tabular}{|c|c|c|c|c|c|c|}
\hline \multirow[b]{4}{*}{ Variable } & \multicolumn{2}{|c|}{ PLWH } & \multicolumn{2}{|c|}{ Control group } & \multirow[b]{4}{*}{ F-ratio } & \multirow[b]{4}{*}{ p-value } \\
\hline & Male & Female & Male & Female & & \\
\hline & $n=15$ & $n=22$ & $n=15$ & $n=22$ & & \\
\hline & Mean \pm S.D & Mean \pm S.D & Mean \pm S.D & Mean \pm S.D & & \\
\hline $6 \mathrm{MWD}$ & $466.22 \pm 89.9^{a}$ & $427.09 \pm 94.32^{a}$ & $600.09 \pm 112.59^{b}$ & $526.07 \pm 64.65^{c}$ & 12.356 & 0.001 \\
\hline $6 \mathrm{MWW}$ & $29001 \pm 5648.5^{a}$ & $27070 \pm 8679.91^{a}$ & $41594 \pm 8149.44^{b}$ & $33962 \pm 5070.20^{c}$ & 14.287 & 0.001 \\
\hline $\mathrm{VO}_{2} \max$ & $2903.6 \pm 564.85^{a}$ & $2710.5 \pm 857.99^{a}$ & $4162.9 \pm 814.94^{b}$ & $3399.7 \pm 507.01^{c}$ & 14.287 & 0.001 \\
\hline PCS & $48.97 \pm 8.33^{a}$ & $53.92 \pm 5.99^{b}$ & $53.74 \pm 5.77$ & $51.49 \pm 8.66$ & 1.662 & 0.183 \\
\hline MCS & $73.62 \pm 9.74^{\mathrm{a}}$ & $72.58 \pm 15.03^{a}$ & $64.03 \pm 7.50^{b}$ & $66.09 \pm 10.39^{b}$ & 2.960 & 0.038 \\
\hline
\end{tabular}

Abbreviations: 6MWD 6 minute walk distance, $6 M W W 6$ minute walk work, VO ${ }_{2}$ max Peak oxygen uptake, PCS Physical-health Component Score, MCS Mental-health Component Score, Superscripts $\left({ }^{\mathrm{a}, \mathrm{b}, \mathrm{c}, \mathrm{d}}\right)$.

For a particular variable, mode means with different superscript are significantly $(P<0.05)$ different. Mode means with same superscripts are not significantly $(P>0.05)$ different. When only one contrast is significant, one of the cell means has no superscript attached. The pair of cell means that is significant has different superscripts.

fatigability, impaired psychosocial and functional capacity that has been associated with HIV infection [7]. The work done during the $6 \mathrm{MWT}$ as revealed by the $6 \mathrm{MWW}$ in this study was also found to be significantly lower among the PLWH. 6MWW is a product of the 6MWD [in meters] and total body weight [in kilograms] [44]. Dourado [68] suggested that several factors including demographic, anthropometric and physiological factors have an effect on the result of the 6MWT. Obese participants usually have reduced lean body mass, leading to a shorter 6MWD. Carter et al. [71] suggested that the weight of the participant may have an effect on the amount of energy used up during the work and thus the distance ambulated. It is believed that this may improve the accuracy and extend the utility of the $6 \mathrm{MWT}$ [71]. Therefore, the $6 \mathrm{MWW}$ is a better reflector of the work done during 6MWT than the 6MWD. Few studies among healthy subjects and patients

Table 5 Pearson product moment correlation between functional exercise capacity variables and each of PCS and MCS

\begin{tabular}{lcc}
\hline Variable & $\begin{array}{c}\text { PLWH } \\
\mathbf{r} \text { (p-value) }\end{array}$ & $\begin{array}{c}\text { Control group } \\
\mathbf{r} \text { (p-value) }\end{array}$ \\
\hline PCS & & \\
$6 \mathrm{MWD}$ & $0.120(0.479)$ & $0.186(0.271)$ \\
$6 \mathrm{MWW}$ & $0.007(0.966)$ & $-0.087(0.607)$ \\
$\mathrm{VO}_{2} \mathrm{max}$ & $0.117(0.485)$ & $0.186(0.271)$ \\
MCS & & \\
$6 \mathrm{MWD}$ & $0.006(0.973)$ & $-0.176(0.296)$ \\
$6 \mathrm{MWW}$ & $0.168(0.321)$ & $0.015(0.932)$ \\
$\mathrm{VO}_{2} \mathrm{max}$ & $-0.016(0.926)$ & $-0.176(0.296)$ \\
\hline
\end{tabular}

Abbreviations: PCS Physical-health Component Score, MCS Mental-health Component Score, $6 M W D$ Six minute walk distance, $6 M W W 6$ minute walk work, $\mathrm{VO}_{2}$ max Peak oxygen uptake. with chronic obstructive pulmonary disease [COPD] have employed the use of the 6MWW [71,72]. However, there seems to be no available study on 6MWW in PLWH.

$\mathrm{VO}_{2}$ max of PLWH in this study were found to be lower than that of the healthy controls. This finding is similar to a report by Rogea et al. [73] who found significantly lower working capacity and the trend towards reduced $\mathrm{VO}_{2} \max$ in PLWH compared to healthy controls. Reduced $\mathrm{VO}_{2}$ max in PLWH may be as a result of reduced oxygen uptake and reduced energy expenditure by PLWH. Pothoff et al. [17] found reduced $\mathrm{VO}_{2}$ max in PLWH at the anaerobic threshold maximal exercise levels when compared with healthy controls. Stringer et al. [18] suggested physiological deconditioning as a causative factor of reduced $\mathrm{VO}_{2}$ max in PLWH. However, physiological deconditioning alone cannot account for the severity of the limitation associated with PLWH [69]. Another explanation for the reduced $\mathrm{VO}_{2}$ max observed in $\mathrm{PLWH}$ especially those in clinical stage I may be due to reduced ability of the exercising musculature to extract and utilize oxygen and highly active anti-retroviral therapy [HAART] also appears to limit peak oxygen uptake [19].

From this study, there were no significant gender differences in the PMFC. However, females with HIV/AIDS had significantly higher PCS while MCS was comparable between both genders. In contrast, the male control subjects had significantly higher values for 6MWD, 6MWW and $\mathrm{VO}_{2}$ max respectively, while PCS and MCS were comparable between both genders. To date, there is limited data concerning women with HIV/AIDS as compared to available data on their male counterparts. Furthermore, there seems to be no available studies comparing functional exercise capacity between male and female PLWH. On the other hand, in concert with the findings of this study, Holzemer et al. [74] demonstrated that HIV positive women possessed higher self-reported quality of life than 
infected men. Also, O'Keefe and Wood [75] in a study conducted in South Africa found that black females with HIV had higher PCS compared with men with HIV.

From this study, there was no significant correlation between self-report and performance-based measure of functional capacity of PLWH and the healthy controls. Literature on the correlation between self-report and performance-based measure of functional capacity of PLWH is scarce. However, a study by Vidrine et al. [76] revealed no association between the functional status and physical and mental health components assessed with the SF-12 in PLWH.

\section{Clinical implications of the study}

This study confirms the findings from many investigators that PLWH are severely deconditioned and face functional aerobic impairment compared to the general population. However, to our knowledge, there seems to be a dearth of studies that have actually compared PLWH with healthy controls. This study found that those with HIV/AIDS had significantly lower functional exercise capacity compared to healthy persons of the same age and gender. In part, the observed significantly lower $\mathrm{VO}_{2}$ max could have resulted from impaired physical fitness revealed by significant lower performance in 6MWT among PLWH. Laura et al. [77] found 6MWT as a valid locomotor performance test of functional capacity in PLWH. Some studies have implicated the use of HAART among PLWH in decreased locomotor performance as a result of direct adverse effects on the muscle and peripheral neurotoxicity [50,78]. Furthermore, this study found that psychosocial constructs such as HRQoL does not influence functional exercise capacity in clinical stage I PLWH. It is implied that HRQoL and functional exercise capacity performance in PLWH are not inter-dependent. Therefore, therapeutic interventions targeted at improving functional exercise capacity in PLWH may not adequately address psychosocial impairment resulting from HIV/AIDS infection.

\section{Limitations of the study}

The outcome of this study cannot be generalized to PLWH in other clinical stages. This is because the clinical stage of HIV/AIDS as well as the progression of the disease has a negative effect on the self-reported quality of life of PLWH [48]. Furthermore, the healthy controls for this study constituted of patients relatives and some health workers at the centre of the study. Relative and caregivers of PLWH have been linked with depression, psychological burden and stress which may affect their overall mental health as a result of poverty and financial struggles induced by HIV/AIDS [79,80]. Therefore, a selection of healthy controls from populations other than those who have contacts with PLWH may yield a different mental health assessment result. Nonetheless, future studies are needed to put these reasonings into empirical analysis.

\section{Conclusion}

Self-report physical health capacity of PLWH and healthy controls was comparable, while self-report mental health capacity was higher in PLWH than the controls. Performance-based functional capacity was lower in clinical stage $1 \mathrm{PLWH}$ compared to the healthy controls. Overall, self-report and performance-based measure of functional exercise capacity of PLWH was not inter-related. Therefore understanding the factors that may influence exercise capacity of PLWH may help to develop effective exercise programmes for PLWH.

Competing interests

The authors declare no competing interest.

\section{Authors' contributions}

CEM conceived the idea for this study, participated in the design of methodology and data collection and analysis and prepared the final manuscript for publication. $\mathrm{O}$ participated in the design of the study's methodology, participated in the interpretation of data and drafted the manuscript. YO participated in the design of methodology and data collection and analysis and drafted the manuscript. OEJ and COA participated in the design of the study's methodology and drafted the manuscript. All authors read and approved the final manuscript.

\section{Acknowledgements}

We would like to acknowledge the Head and all clerical and clinical staff of the Virology Research Clinic of Obafemi Awolowo University Teaching Hospitals Complex (OAUTHC) lle-lfe, Nigeria for their support in caring out this study.

\section{Author details}

'Department of Medical Rehabilitation, College of Health Sciences, Obafemi Awolowo University, lle - Ife, Nigeria. ${ }^{2}$ Department of Dermatology and Veneriology, Faculty of Clinical Sciences, College of Health Sciences, Obafemi Awolowo University, Ile - Ife, Nigeria. ${ }^{3}$ Department of Physiotherapy,

Obafemi Awolowo University Teaching Hospitals Complex, Ile - Ife, Nigeria. ${ }^{4}$ Department of Medical Rehabilitation, College of Health Sciences, Nnamdi Azikiwe University, Nnewi Campus, Nnewi, Anambra State, Nigeria.

Received: 28 December 2012 Accepted: 19 June 2013

Published: 26 June 2013

\section{References}

1. UNAIDS: AIDS epidemic update. 2007. http://data.unaids.org/pub/EPISlides/ 2007/2007_epiupdate_en.pdf [Accessed 19/01/2009]

2. Worldwide AIDS \& HIV Statistics: 2009 Quarterly HIV/AIDS statistics. AVERT. Office of AIDS; 2011. http://www.avert.org/worldstats.htm. Accessed 20/06/11.

3. World Health Organization. Global Health Observatory (GHO): Prevalence of HIV among adults aged 15-49 (\%). Situation and trends. 2010. http://www. who.int/gho/hiv/epidemic status/prevalence_text/en/index.html [Accessed 22/06/2009].

4. UNAIDS/WHO: AIDS epidemic update. Geneva, Switzerland; 2003. Available from http://www.unaids.org/wad/2003/press/Epiupdate2003_en/ Epi03_00_en.htm [Accessed 21/06/2011].

5. UNAIDS: AIDS epidemic update: World Health Organization. Geneva: UNAIDS/ 07.27E/JC1322E; 2007.

6. UNGASS country progress report. Nigeria; 2010. http://www.unaids.org/en/ regionscountries/countries/nigeria/ [Accessed 22/06/2011].

7. Bopp CM, Phillips KD, Fulk LJ, Hand GA: Clinical implications of therapeutic exercise in HIV/AIDS. J Assoc Nurses AIDS Care 2003, 14(1):73-78.

8. Cushion J: HIV and AIDS research paper 95/88. House of Commons Library: Science and environment section; 1995:1-38.

9. Dropulic B, Humeau L, Binder GK, Lu X, Slepushkin V, Merling R, et al: 1003. HIV-1-derived lentivirus vector-based antisense gene therapy: 
towards an alternative treatment for HIV/AIDS. Mol Ther 2004, 9:\$384-\$384.

10. Schambelan M, Mulligan K, Grunfeld C, Daar ES, LaMarca A, Kotler DP, Wang J, Bozzette SA, Breitmeyer JB: Recombinant human growth hormone in patients with HIV-associated wasting. A randomized, placebo-controlled trial. Serostim study group. Ann Intern Med 1996, 125(11):873-882.

11. Basaria S, Wahlstrom JT, Dobs AS: Clinical review 138: anabolic-androgenic steroid therapy in the treatment of chronic diseases. J Clin Endocrinol Metabol 2001, 86(11):5108-5117.

12. Standish L, Greene KB, Bain S, Reeves C, Sanders F, Wines RC, et al: Alternative medicine use in HIV-positive men and women: demographics, utilization patterns and health status. AIDS Care 2001, 13(2):197-208.

13. Holzemer WL, Wilson HS: Quality of life and the spectrum of HIV infection. Annu Rev Nurs Res 1995, 13:3-29.

14. Wilson IB, Cleary PD: Linking clinical variables with health-related quality of life: a conceptual model of patient outcomes. JAMA 1995, 273:59-65.

15. Douaihy $A$, Singh N: Factors affecting quality of life in patients with HIV infection. AIDS Read 2001, 11(9):450-461.

16. O'Brien K, Nixon S, Tynan AM, Glazier RH: Effectiveness and safety of aerobic exercise in adults living with HIV/AIDS: systematic review and meta-analysis of randomized trials. Med Sci Sports Exerc 2004, 36:1659-1666.

17. Pothoff G, Wassermann K, Ostmann H: Impairment of exercise capacity in various groups of HIV-infected patients. Respiration 1994, 61(2):80-85

18. Stringer WW, Berezovskaya M, O'Brien WA, Beck CK, Casaburi R: The effect of exercise training on aerobic fitness, immune indices, and quality of life in HIV+ patients. Med Sci Sports Exerc 1998, 30(1):11-16.

19. Cade WT, Fantry LE, Nabar SR, Shaw DK, Keyser RE: A comparison of Qt and a- $\mathrm{VO}_{2}$ in individuals with HIV taking and not taking HAART. Med SCi Sports Exerc 2003, 35(7):1108-1117.

20. Leserman J, Petitto JM, Perkins DO, Folds JD, Golden RN, Evans L: Severe stress, depressive symptoms, and changes in lymphocyte subsets in human immunodeficiency virus-infected men. A 2-year follow-up study. Arch Gen Psychiatry 1997, 54(3):279-285.

21. Cruess DG, Antoni MH, Schneiderman N, Ironson G, McCabe P, Fernandez JB, Cruess SE, Klimas N, Kumar M: Cognitive-behavioral stress management increases free testosterone and decreases psychological distress in HIV-seropositive men. Health Psychol 2000, 19(1):12-20.

22. Antoni MH, Cruess DG, Klimas N, Maher K, Cruess S, Kumar M, Lutgendorf S, Ironson G, Schneiderman N, Fletcher MA: Stress management and immune system reconstitution in symptomatic HIV-infected gay men over time: effects on transitional naive T cells (CD4(+)CD45RA(+)CD29 (+)). Am J Psychiatry 2002, 159(1):143-145

23. Meyer K, Görnandt L, Schwaibold M, Westbrook S, Hajric R, Peters K, Beneke $R$, Schnellbacher $K$ : Predictors of response to exercise training in severe chronic congestive heart failure. HSO Am J Cardiol 1997, 80(1):56.

24. Nieman DC, Johanssen LM, Lee JW, Arabatzis K: Infectious episodes in runners before and after the Los Angeles Marathon. J Sports Med Phys Fitness 1990, 30(3):316-328.

25. Roubenoff R, Skolnik PR, Shevitz A, Snydman L, Wang A, Melanson S, Gorbach S: Effect of a single bout of acute exercise on plasma human immunodeficiency virus RNA levels. J App/ Physiol 1999, 86(4):1197-1201.

26. Ciccolo JT, Jowers EM, Bartholomew JB: The benefits of exercise training for quality of life in HIV/AIDS in the post-HAART Era. Sports Med 2004, 34(8):487-499.

27. Esposito JG, Thomas SG, Kingdon L, Ezzat S: Anabolic growth hormone action improves submaximal measures of physical performance in patients with HIV-associated wasting. Am J Physiol Endocrinol Metab 2005, 289:E494-E503.

28. Sterne JA, Herna'n MA, Ledergerber $B$, et al: Long-term effectiveness of potent antiretroviral therapy in preventing AIDS and death: a prospective cohort study. Lancet 2005, 366:378-384

29. Edwards M: The reliability and validity of self report activities of daily living. Can J Occup Ther 1990, 57(5):273-278.

30. Falconer J, Hughes S, Naughton B, Singer R, Chang R, Sinacore J: Self report and performance-based hand function tests as correlates of dependency in the elderly. J Am Ger Soc 1991, 39:695-699.

31. Matheson L, Matheson M, Grant J: Development of a measure of perceived functional ability. J Occup Rehabil 1993, 3(1):15-30

32. Kuhn R, Rahman O, Menken J: Survey Measures of Health: How Well do self-reported and observed indicators measures health and Predict
Mortality? Chapter 10. In Barney Cohen and Jane Menken aging in Sub-Saharan Africa: Recommendation for furthering research. Research Council (US) Committee on Population: National Academies Press (US); 2006:314-342.

33. Dorevitch Ml, Cossar RM, Bailey FJ, et al: The accuracy of self and informant ratings of physical functional capacity in the elderly. J Clin Epidemiol 1992, 45:791-798.

34. Myers AM, Holliday PJ, Harvey A, et al: Functional performance measures: are they superior to self-assessment? J Gerontol A Biol Sci Med Sci 1993 48:M196-M206.

35. Kuijer W, Gerrits EHJ, Reneman MF: Measuring physical performance via self-report in healthy young adults. J Occup Rehabil 2004, 14(1):77-87.

36. Centers for Disease Control and Prevention (CDC): Revised classification system for HIV infection and expanded surveillance case definition for AIDS among adolescents and adults. MMWR Recomm Rep 1993, 18:41:1-19.

37. World Health Organization: WHO case definitions of HIV for surveillance and revised clinical staging and immunological classification of HIV-related disease in adults and children. 2007. www.who.int/hiv/pub/guidelines/ HIVstaging150307.pdf [Accessed 22/06/2011].

38. Delate T, Coons SJ: The discriminative ability of the 12-Item short form health survey (SF-12) in a sample of persons infected with HIV. Clin Ther 2001, 22(9):1112-1120.

39. Lam CL, Tse EY, Gandek B: Is the standard SF-12 health survey valid and equivalent for a Chinese population? Qual Life Res 2005, 14(2):539-547.

40. Montazeri A, Vahdaninia M, Mousavi SJ, Asadi-Lari M, Omidvari S, Tavousi M: Health Qual Life Outcomes 2011, 7;9:1

41. Han C, Pulling CC, Telke SE, Huppler Hullsiek K: Terry Beirn Community Programs for Clinical Research on AIDS. Assessing the utility of five domains in SF-12 Health Status Questionnaire in an AIDS clinical trial. AIDS 2002, 15;16(3):431-439.

42. Grossman HA, Sullivan PS, Wu AW: Quality of life and HIV: Current Assessment Tools and Future Directions for Clinical Practice. AlDS Read 2003, 13(12):583-597.

43. American Thoracic Society Statement (ATS): Guidelines for the six-minute walk test. Am J Respir Crit Care Med 2002, 166:111-117.

44. Chuang ML, Lin IF, Wasserman K: The body weight-walking distance product as related to lung function, anaerobic threshold and peak $\mathrm{VO}_{2}$ in COPD patients. Respir Med 2001, 95:618-626.

45. American College of Sport Medicine (ACSM): Guidelines for Graded exercise testing and exercise prescription. 5th edition. Philadelphia (PA): Lea \& Febiger; 1995:172-175.

46. Franchi D, Wenzel RP: Measuring health-related quality of life among patients infected with human immunodeficiency virus. Clin Infect Dis 1998, 26:20-26.

47. Marins JR, Jamal LF, Chen SY, Barros MB, Hudes ES, Barbosa AA: Dramatic improvement in survival among adult Brazilian AIDS patients. AIDS 2003, $17: 1675-1682$

48. Nojomi M, Anbary K, Ranjbar M: Health-related quality of life in patients with HIV/AIDS. Arch Iran Med 2008, 11(6):608-612.

49. Nirmal B, Divya KR, Dorairaj VS, Venkateswaran K: Quality of life in HIV/AIDS patients: A cross-sectional study in south India. Indian Journal of Sexually transmitted diseases and AIDS 2008, 29(1):15-17.

50. Moyle G: Clinical manifestations and management of antiretroviral nucleoside analog-related mitochondrial toxicity. Clin Ther 2000, 22:911-936.

51. Rabkin JG, Johnson J, Lin SH, Lipsitz JD, Remien RH, Williams JB, Gorman JM: Psychopathology in male and female HIV-positive and negative injecting drug users: longitudinal course over 3 years. AIDS 1997, 15;11(4):507-515.

52. Nokes KM, Kendrew J: Correlates of sleep quality in persons with HIV disease. J Assoc Nurses AIDS Care 2001, 12(1):17-22

53. Turner BJ, Laine C, Cosler L, Hauck WW: Relationship of gender, depression, and health care delivery with antiretroviral adherence in HIV-infected drug users. J Gen Intern Med 2003, 18:248-257.

54. Aranda-Naranjo B: Quality of life in the HIV-positive patient: implications and consequences. J Assoc Nurses AIDS Care 2004, 15(5 Suppl):20S-27S.

55. Ostrow D, Liu C, Detels R, Hu Z, Johnson C, Kingsley L, Jacobson LP: Impact of HIV infection \& HAART use on quality of life. Qual Life Res 2006, 15:941-949.

56. Adewuya A, Makanjuola R: Preferred treatment for mental illness among southwestern Nigerians. Psychiatr Serv 2009, 60(1):121-124.

57. Pargament Kl, McCarthy S, Shah P, Ano G, Tarakeshwar N, Wachholtz A, Sirrine N, Vasconcelles E, Murray-Swank N, Locher A, Duggan J: Religion and HIV: a review of the literature and clinical implications. South Med $J$ 2004, 97(12):1201-9. 
58. Oyebola FO: A Case Study from Nigeria: The added value of spiritual care and support in a terminally ill-patient and family. J Palliat Med. http://www. palliativejournal.stanford.edu/?p=3623 Accessed on 06/08/2012.

59. Tsevat J: Spirituality/Religion and Quality of Life in Patients with HIV/ AIDS. J Gen Intern Med 2006, 21(S5):S1-S2.

60. Tsevat J, Sherman SN, McElwee JA, Mandell KL, Simbartl LA, Sonnenberg FA Fowler FJ Jr: The will to live among HIV-infected patients. Ann Intern Med 1999, 3;131(3):194-8.

61. Sowell R, Moneyham L, Hennessy M, Guillory J, Demi A, Seals B: Spiritual activities as a resistance resource for women with human immunodeficiency virus. Nurs Res 2000, 49:73-82.

62. Grimsley LP: Spirituality and quality of life in HIV-positive persons. J Cult Divers 2006, 13:113-8.

63. Cotton S, Puchalski CM, Sherman SN, Mrus JM, Peterman AH, Feinberg J, Pargament Kl, Justice AC, Leonard AC, Tsevat J: Spirituality and religion in patients with HIV/AIDS. J Gen Intern Med 2006, 21(Suppl 5):S5-13.

64. Hall BA: Patterns of spirituality in persons with advanced HIV disease. Res Nurs Health 1998, 21:143-53.

65. Siegel K, Schrimshaw EW: The perceived benefits of religious and spiritual coping among older adults living with HIV/AIDS. Journal for the Scientific Study of Religion 2002, 41:91-102.

66. Somlai AM, Heckman TG: Correlates of spirituality and well-being in a community sample of people living with HIV disease. Mental Health, Religion and Culture 2000, 3:57-70.

67. Tuck I, McCain NL, Elswick RK Jr: Spirituality and psychosocial factors in persons living with HIV. J Adv Nurs 2001, 33:776-83.

68. Dourado VZ: Reference Equations for the 6-Minute Walk Test in Healthy Individuals. Ara Bras Cardiol 2011, 96:6:e128-138.

69. Cade WT, Peralta L, Keyser RE: Aerobic capacity in late adolescents infected with HIV and controls. Pediatr Rehabil 2002, 5(3):161-9.

70. Cade WT, Fantry LE, Nabar SR, Keyser RE: Decreased peak arteriovenous oxygen difference during treadmill exercise testing in individuals infected with the human immunodeficiency virus. Arch Phys Med Rehabil 2003, 84(11):1595-603.

71. Carter R, Holiday DB, Nwasuruba C, Stocks J, Grothues C, Tiep B: 6-minute walk work for assessment of functional capacity in patients with COPD. Chest 2003, 123(5):1408-1415.

72. Hill K, Jenkins SC, Cecins N, Philippe DL, Hillman DR, Eastwood PR: Estimating maximum work rate during incremental cycle ergometry testing from six-minute walk distance in patients with chronic obstructive pulmonary disease. Arch Phys Med Rehabil 2008, 89:1782-1787.

73. Rogea BT, Calbetb JAL, Mollera K, Ulluma H, Hendelc HW, Gerstofta J, Pedersena BK: Skeletal muscle mitochondrial function and exercise capacity in HIV-infected patients with lipodystrophy and elevated p-lactate levels. AIDS 2002, 16:973-982.

74. Holzemer WL, Gygax Spicer J, Skodol Wilson H, Kemppainen JK, Coleman C: Validation of the quality of life scale: living with HIV. J Adv Nurs 1998, 28(3):622-30.

75. O'Keefe EA, Wood R: The impact of human immunodeficiency virus (HIV) infection on quality of life in a multiracial South African population. Qual Life Res 1996, 5(2):275-80.

76. Vidrine DJ, Amick BC 3rd, Gritz ER, Arduino RC: Functional status and overall quality of life in a multiethnic HIV-positive population. AIDS Patient Care STDS 2003, 17(4):187-97.

77. Laura $R$, Patrick D, Patrick $M$, Frédéric-Antoine $D$, Mathias B, Carinec $G$, François D, Fabrice B, Geneviève C, For the Groupe d'Epidémiologie Clinique du SIDA en Aquitaine (GECSA): High frequency of poor locomotor performance in HIV-infected patients. AIDS 2011, 25(6):797-805.

78. Scruggs ER, Dirks Naylor AJ: Mechanisms of zidovudine-induced mitochondrial toxicity and myopathy. Pharmacology 2008, 82:83-88.

79. Wekesa E: The impact of HIV/AIDS on child survival and development in Kenya. AIDS Anal Af 2000, 10:12-14.

80. Catz SL, Gore-Felton C, McClure JB: Psychological distress among minority and low-income women living with HIV. Behav Med 2002, 28:53-60.

doi:10.1186/1477-7525-11-106

Cite this article as: Mbada et al:: Health-related quality of life and physical functioning in people living with HIV/AIDS: a case-control design. Health and Quality of Life Outcomes 2013 11:106.

\section{Submit your next manuscript to BioMed Central and take full advantage of:}

- Convenient online submission

- Thorough peer review

- No space constraints or color figure charges

- Immediate publication on acceptance

- Inclusion in PubMed, CAS, Scopus and Google Scholar

- Research which is freely available for redistribution 